both cases, and no brick-red zone could be observed above the yellow one.

Since Carter et al. ${ }^{3}$ and Kylin ${ }^{5}$ state that Ceramium rubrum contains both $a$ - and $\beta$-carotene, we also carried out a comparison between this alge and Rhodymenia. Chromatography of the light petroleum extract on magnesium oxide and calcium hydroxide showed exectly the same picture for both species, and the isolated pigments were indistinguishable with respect to their absorption spectra in carbon disulphide. According to these experiments, therefore, we find it safe to conclude that Rhodymenia palmata contains both $\alpha$ - and $\beta$-carotene.

Several other species of Rhodophyceae were investigated along the same lines. The results are given in Table 1. The results from earlier investigations are shown in the same table. As the table shows, 11 of the 16 investigated species were found to contain a-carotene.

The table also shows the total amounts of carotene $(\alpha+\beta)$ given as $\mathrm{mg}$ per 1000 $g$ dry matter. The amounts were found to depend strongly on the season and the treatment of the samples. The figures given here should, however, give a fairly correct picture of the variation between the species during the summer months.

The relative amounts of $\alpha$-and $\beta$-carotene were determined in 6 species. The results are given in Table 2 as the amount of $\alpha$-carotene divided by the amount of $\beta$-carotene. The amounts are calculated from the optical densities in carbon disulphide and the molar extinction of $\alpha$ - and $\beta$-carotene in the same solvent. As the table shows, the amount of $a$-carotene in the investigated species was of the same order of magnitude as that of $\beta$. Delesseria sanguinea was found to be particularly rich in $\alpha$-carotene. Contrary to the total amounts of carotene, the relative amounts seemed to be approximately constent, independent of the season (samples from the winter months were not investiga. ted) and the treatment of the samples.

Phycodrys sinuosa differed markedly from the other investigated species, as in

Table 2.

$\begin{array}{ll} & \alpha / \beta \\ \text { Delesseria sanguinea } & 3.1 \\ \text { Rhodymenia palmata } & 1.4 \\ \text { Furcellaria fastigiata } & 1.3 \\ \text { Ceramium rubrum } & 0.5 \\ \text { Gigartina stellata } & 0.5 \\ \text { Dumontia incrassata } & 0.4\end{array}$

this alga we were not able to show the presence of $\beta$-cerotene. Samples from different localities and collected at different seasons gave the same result. We are thus forced to conclude that Phycodrys sinuosa either has a specific mechanism for a rapid destruction of $\beta$-carotene, or that the amount of $\beta$-carotene, if this is present at all, was very small compared with $\alpha$-carotene. Whatever the explanation may be, this species seems to deserve a further investigation.

Acknowledgements. This work forms part of the research program of the Norwegian Institute of Seaweed Research. We are indebted to professor N. A. Sørensen for inspiring interest and helpful suggestions, to one of the algologists of the Institute, Dr. E. Baardseth, for collecting and identifying the material, and to Miss S. Svendsen for skilful assistance with the analyses.

1. Heilbron, I. M., Parry, E. G. and Phipers, R. F. Biochem. J. London 29 (1935) 1376.

2. Haug, A. and Larsen, B. Acta Chem. Scand. 10 (1956) 472.

3. Carter, P. W., Heilbron, I. M. and Lythgoe, B. Proc. Roy. Soc. London 128B (1940) 82.

4. Seybold, A. und Egle, K. Jahrb. wiss. Botan. 86 (1938) 50.

5. Kylin, H. Hoppe-Seyler's Z. physiol. Chem. 74 (1911) 105.

6. Kylin, H. Ibid. 166 (1927) 39.

Received February 24, 1956.

\section{Carotene Breakdown in Rhodymenia palmata (L.) Grev.}

ARNE HAUG and BJøRN LARSEN

Norwegian Institute of Seaweed Research, Trondheim, Norway

$D^{\mathrm{u}}$ uring an investigation of the carotene breakdown in some Norwegian seaweeds and seaweed meals an extraordinary rapid loss of carotene was observed in the red alga Rhodymenia palmata. This alga, therefore, seemed to be a convenient object for further studies of the breakdown mechanism. The carotene present in Rhodymenia palmata was found to consist of about equal amounts of the $\alpha$ - and $\beta$-isomers ${ }^{1}$. 
Table 1.

Drying conditions

Carotene content as per cent of the content of the fresh samples

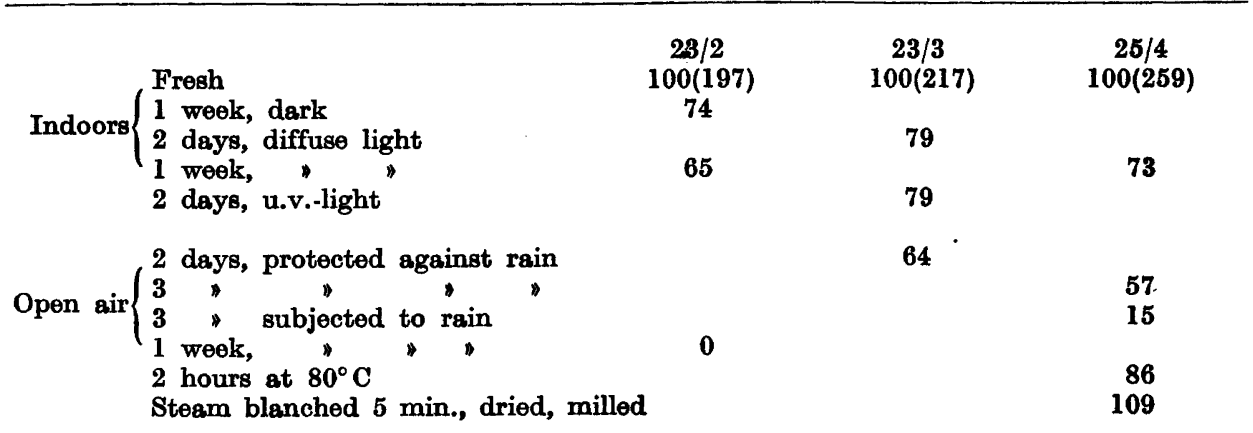

The analytical procedure used for the quantitative determination of carotene has been described in a previous paper ${ }^{1}$. Estimation of the carotene content in fresh samples needed special attention. The quantitative extraction of carotene from fresh Rhodymenia palmata was found to be difficult to accomplish. The highest values for fresh a lga $\theta$ were obtained when the material was ground in a mortar with quartz sand and solid carbon dioxide, followed by immediate extraction with acetone. However, as will be shown below, still higher values for the initial carotene content in the samples, and which we think are more reliable, were obtained when the samples were steam blanched and dried overnight.

In order to determine the influence of light, heat and rain on the breakdown rate, three series of simple drying experiments were carried out. The results are shown in Table 1. The figures in brackets refer to the carotene content in fresh samples given as mg carotene per $1000 \mathrm{~g}$ dry matter. The amount of carotene in the samples increased from February to April due to seasonal variation.

It will be seen that the breakdown rate was approximately the same for samples dried in darkness, in diffuse light or in ultraviolet light, while samples dried in open air, subjected to direct sunlight, showed a more rapid breakdown. The results seem to indicate that the reaction is slightly photosensitive, and that the active part of the spectrum is in the visible region. This observation is in good agreement with observations by Griffith and
Thompson ${ }^{2}$ for the carotene breakdown in alfalfa during drying.

When the samples were dried at $80^{\circ} \mathrm{C}$ only a slight breakdown was observed, while steam blanching led to no carotene loss. The steam blanched samples could be dried overnight without any breakdown taking place. That the figure for the steam blanched sample is higher than for the fresh material is supposed to be due to incomplete extraction of the latter and to small losses of dry matter during the steam blanching.

The samples dried in open air and subjected to rain during the drying period lost their carotene content very rapidly compared with samples protected against rain.

The results from the drying experiments indicated that the carotene breakdown in Rhodymenia palmata might be of enzymatic nature. To further establish this, some experiments with fresh material were carried out.

If the fresh alga was stored before carotene determination a considerable carotene loss was observed. A sample blanched within 1 hour after harvesting was found to contain $280 \mathrm{mg}$ carotene per $1000 \mathrm{~g}$ dry matter. When the sample was stored for 20 hours before blanching only $135 \mathrm{mg}$ per $1000 \mathrm{~g}$ dry matter (48 \%) was found.

If the sample was ground as described above, and allowed to thaw before acetone was added, the breakdown was extremely rapid as shown in Table 2. Attempts were made to inhibit this breakdown by means of enzyme inhibitors. The inhibitors were ground together with the samples in the mortar in concentrations of approximately 
Table 2.

Treatment
Carotene content as per cent of the content of the fresh samples

$\begin{array}{cc}23 / 3 & 25 / 4 \\ 100(217) & 100(259) \\ 0 & 63 \\ & 16 \\ & 78 \\ & 91 \\ & 30 \\ & 0 \\ & 29\end{array}$

$0.5 \%$ and the samples set aside for 20 hours before acetone was added. It will be seen from Table 2 that sodium fluoride had no effect and that mercury chloride was only slightly effective. A slight inhibition was also observed when the sample was stored in a vacuum desiccator at a pressure of approximately $20 \mathrm{~mm} \mathrm{Hg}$. On the other hand, both potassium cyanide and sodium sulphide were fairly effective. The inhibition obtained with sodium sulphide may be due to the anaerobic conditions set up by this substance. In the case of potassium cyanide, however, the effect must be due to the inhibition of an enzymatic reaction. It seems, therefore, to be safe to conclude, that an enzymatic reaction must be involved in the carotene breakdown in Rhodymenia palmata.

A similar inhibition of the carotene breakdown by means of potassium cyanide was observed in alfalfa by Mitchell and Hauge in $1946^{\circ}$. The enzyme system responsible for the carotene breakdown in alfalfa has later been found to be lipoxidase. The carotene is oxidised by some of the intermediate reaction products formed in the enzymatic oxidation of unsaturated fatty acids. Whether a similar reaction is responsible for the destruction of carotene in Rhodymenia palmata has not been established.

Acknowledgements. This work forms part of the research program of the Norwegian Institute of Seaweed Research. We are indebted to professor N. A. Sørensen for inspiring interest and helpful suggestions, and to Miss S. Svendsen for skilful assistance with the analyses.

1. Larsen, B. and Haug, A. Acta Chem. Scand. 10 (1956) 470.
2. Griffith, R. B. and Thompson, C. R. Botan. Gaz. 111 (1950) 165.

3. Mitchell, H. L. and Hauge, S. M. J. Biol. Chem. 163 (1946) 7.

Received February 24, 1956.

Demonstration of Reichstein's Substance $S$ in Dog Adrenal Vein Blood by Countercurrent Distribution

HANS CARSTENSEN

Institute of Physiology, University of Upsala, Upsala, Sweden

The two major corticosteroids of dog 1 adrenal vein blood, from a quantita. tive point of view, are cortisol and corticosterone, as demonstrated by several physical and chemical methods ${ }^{1-4}$. Among other possible components, the presence of minor amounts of Reichstein's substance $S \quad\left(\Delta^{4}\right.$-pregnene-17a,2l-diol-3,20dione) seems to have considerable interest ${ }^{5}$ (cf. Eberlein et al. ${ }^{6}$ ).

Further evidence of its occurrence in dog adrenal vein blood is provided here by its demonstration after countercurrent distribution. A sample of $330 \mathrm{ml}$ blood was collected from the left adrenal of a mongrel male dog weighing $18 \mathrm{~kg}$ during 60 minutes and extracted with ethyl acetate as previously outlined 4. The common corticosteroid fraction was recovered from the polar phase after double distribution between $n$-hexane and $50 \%$ ethanol in water and subjected to successive countercurrent distributions (Table 1).

Acta Chem. Scand. 10 (1956) No. 3 